\title{
ESTUDO TEÓRICO E LEVANTAMENTO BIBLIOGRÁFICO SOBRE SÍNTESE E CARACTERIZAÇÃO DE NANOPARTÍCULAS SEMICONDUTORAS COLOIDAIS FLUORESCENTES
}

\author{
$\underline{\text { Ricardo Macedo Borges Boaventura }}{ }^{1}$; Ernando Silva Ferreira ${ }^{2}$ \\ 1. Bolsista PROBIC/UEFS, Graduando em Bacharelado em Física, Universidade Estadual de Feira de Santana, e- \\ mail: ricardombboaventura@gmail.com \\ 2. Orientador, Departamento de Física, Universidade Estadual de Feira de Santana, e-mail: \\ ernandofisica@yahoo.com.br
}

\begin{abstract}
PALAVRAS-CHAVE: nanocristais semicondutores; coloides; síntese de nanopartículas.
\end{abstract}

\section{INTRODUÇÃO}

Nanopartículas semicondutoras com diâmetro variando de um a dez nanômetros tem sido objeto de grande atenção da comunidade científica. Essas partículas situam-se no regime de transição entre o sólido de bulk e suas moléculas e se mostram úteis no estudo de propriedades particularmente novas da matéria descritas pelo termo "efeito de quantização do tamanho" (Caruso, 2006).

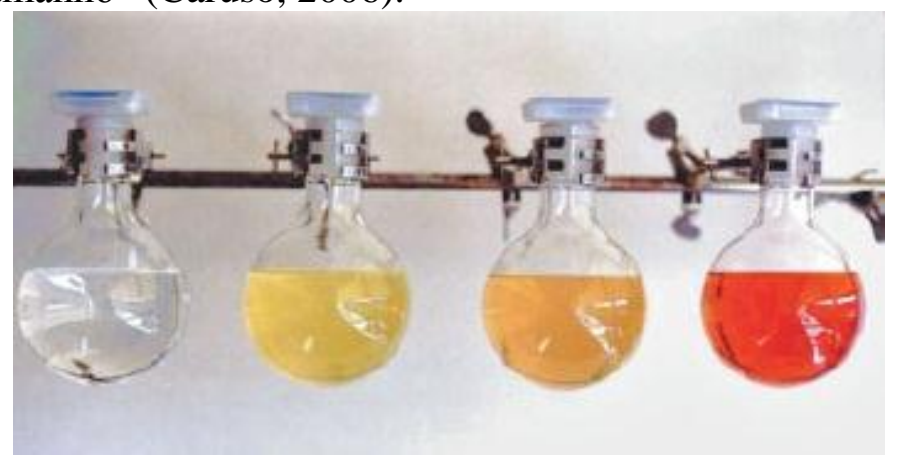

Figura 1: Manifestação do efeito de quantização do tamanho em soluções coloidais de nanopartículas de Seleneto de Cádmio (CdS). O tamanho das partículas varia da esquerda para a direita de $1,5 \mathrm{~nm}$ até $4,5 \mathrm{~nm}$.

Síntese coloidal de nanopartículas em solventes apropriados é geralmente chamada de síntese "bottom up" (de baixo para cima). No estado atual, no qual se encontra a tecnologia, ainda é muito difícil alcançar essa ordem de grandeza no diâmetro das partículas por meio de técnicas "top down" (de cima para baixo), como técnicas baseadas em litografia, por exemplo. Utilizando rotas químicas bottom up, e possível obter diversas nanopartículas semicondutoras de alta qualidade numa escala de gramas, manuseáveis como produtos químicos ordinários e com potencial para serem utilizadas na criação de substratos para estruturas supramoleculares e dispositivos. Aqui, alta qualidade se refere a partículas do tamanho desejado, distribuição de tamanhos estreita, boa cristalinidade, funcionalização de superfície controlável e alta eficiência quântica de luminescência (Caruso, 2006).

A qualidade de semicondutor de um macrocristal, o sólido de bulk, vem do arranjo dos átomos numa rede cristalina. A sobreposição dos orbitais atômicos transforma os níveis discretos de energia possíveis para um elétron em bandas contínuas separadas por uma banda proibida (bad gap). Quando excitado pela absorção de um fóton, um elétron na banda de valência salta para a banda de condução, deixando um "buraco" que age como uma carga positiva e sofre atração coulombiana com o elétron. O par elétron-buraco é chamado de éxciton (Caruso, 2006). Na escala em que se encontram as nanopartículas, 
cada uma delas é de tamanho comparável ao raio de Bohr do éxciton no sólido de bulk, dando origem a efeitos de confinamento quântico, onde as propriedades optoeletrônicas da partícula podem ser controladas alterando suas dimensões (Gerion, et al, 2001).

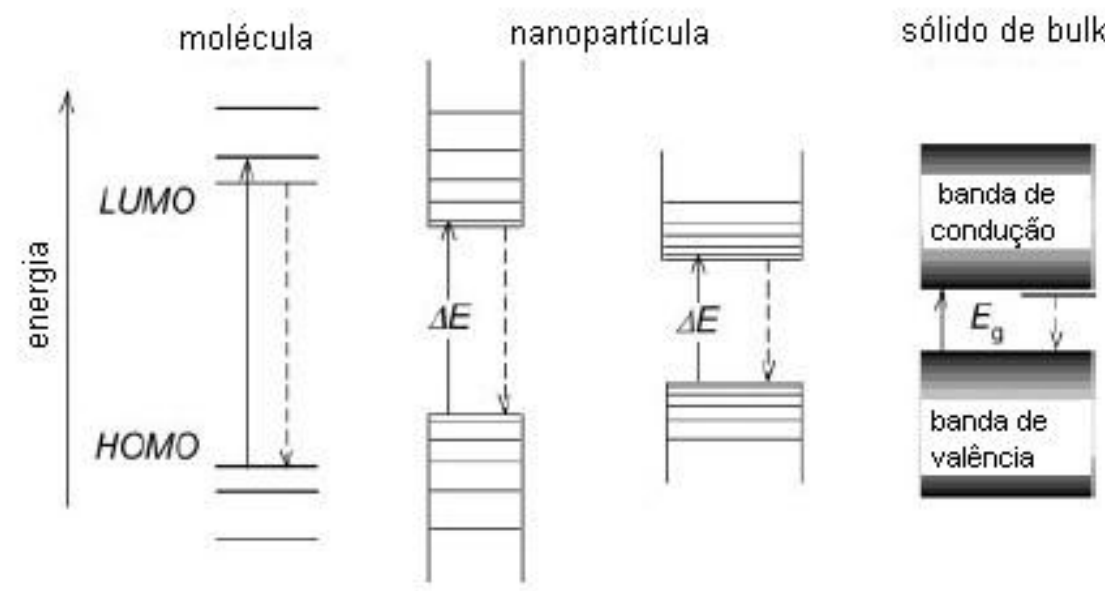

Figura 2: Diagrama ilustrando a situação das bandas de energia numa nanopartícula, entre uma molécula e o solido de bulk.

Essas propriedades ajustáveis abrem espaço para diversas aplicações, em especial, aplicações biológicas (Farias, 2006). Visando ampliar os horizontes nessa área do conhecimento, foi desenvolvido um estudo teórico sobre as técnicas de síntese e caracterização de nanopartículas semicondutoras, visando a implantação de futuros projetos na área.

\section{METODOLOGIA}

O levantamento bibliográfico foi feito utilizando de bancos de dados eletrônicos que fornecem acesso a publicações em periódicos, livros e outras obras nessa área. Os motores de busca foram configurados de modo a exibir resultados contendo as palavras chave referentes ao tipo de nano partícula estudado (coloidais semicondutoras fluorescentes/quantum dots) no título e corpo do texto. No entanto, buscando pelas palavras chave também no corpo do texto, foram exibidos resultados que continham de fato as palavras chave, mas num contexto que tornava tais resultados irrelevantes para a pesquisa. Para selecionar as publicações relevantes, foram estudados os resumos dos artigos encontrados com as palavras chave especificadas em busca de rotas de síntese que utilizassem materiais de baixo custo, toxicidade e periculosidade no manejo além de equipamentos e reagentes já disponíveis em laboratório ou de fácil aquisição.

\section{RESULTADOS E DISCUSSÃO}

As buscas realizadas utilizando a metodologia descrita retornaram o seguinte número de resultados por conjunto de palavras chave

Tabela 1. Número $n$ de resultados por palavras chave

Palavras chave

colloidal fluorescent semiconductor nanoparticles

colloidal fluorescent semiconductor quantum dots

$n$
1
2
5
1

synthesis of fluorescent semiconductor nanoparticles colloidal synthesis graphene quantum dots

O uso dessas mesmas palavras chave em português não retornou resultado algum. A maior parte dos resultados já traz técnicas de caracterização e seus resultados. No entanto, quase todos eles utilizam rotas complexas ou com materiais de alta toxicidade, como o Seleneto de Cádmio, e a síntese radiolítica, utilizando raios gama. Ainda assim, um dos resultados traz a síntese coloidal de nanopartículas de grafeno, que pode ser 
realizada utilizando materiais e reagentes de fácil manipulação e obtenção. Mesmo que o restante da bibliografia encontrada não apresente técnicas praticáveis em laboratório atualmente, tal matéria proporciona um grande enriquecimento do arcabouço teórico nessa área, além de fomentar futuros projetos.

\section{CONSIDERAÇÕES FINAIS (ou Conclusão)}

Com base nos métodos de síntese descritos na literatura reunida ao longo na realização do plano de trabalho, a produção de nanocristais semicondutores coloidais fluorescentes é factível com o material disponível em laboratório, viabilizando a realização de projetos futuros na área. Os textos produzidos durante o estudo dos conceitos envolvidos nos métodos de síntese e caracterização encontrados servirão de base e material de consulta durante a realização dos próximos projetos.

\section{REFERÊNCIAS}

CARUSO, Frank (Ed.). Colloids and colloid assemblies: synthesis, modification, organization and utilization of colloid particles. John Wiley \& Sons, 2006.HENNIG, W. 1981. Insect phylogeny. Chichester, John Wiley, 514p.

GERION, Daniele et al. Synthesis and properties of biocompatible water-soluble silicacoated CdSe/ZnS semiconductor quantum dots. J. Phys. Chem. B, v. 105, n. 37, p. 8861-8871, 2001.

FARIAS, Patrícia MA et al. Application of colloidal semiconductor quantum dots as fluorescent labels for diagnosis of brain glial cancer. In: Proc. of SPIE Vol. 2006. p. 60961B-1. 